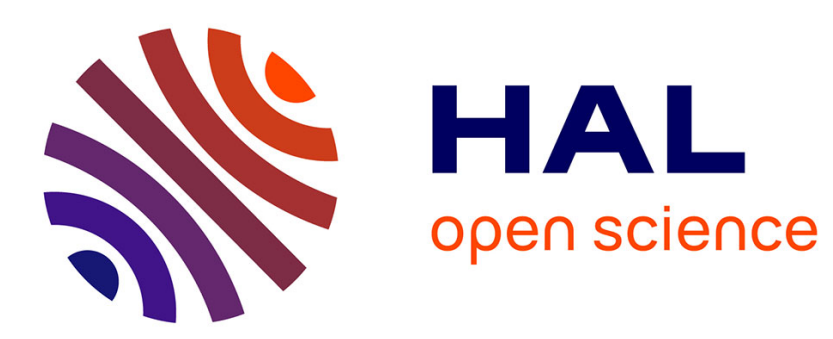

\title{
Mixed Alkali Effect in Na2O-Li2O-Si O2 Glasses Studied by Isothermal Mechanical Spectroscopy
}

\author{
C. Tardif, L. Arnault, A. Rivière
}

\section{To cite this version:}

C. Tardif, L. Arnault, A. Rivière. Mixed Alkali Effect in Na2O-Li2O-Si O2 Glasses Studied by Isothermal Mechanical Spectroscopy. Journal de Physique IV Proceedings, 1996, 06 (C8), pp.C8-711C8-714. 10.1051/jp4:19968155 . jpa-00254589

\section{HAL Id: jpa-00254589 https://hal.science/jpa-00254589}

Submitted on 1 Jan 1996

HAL is a multi-disciplinary open access archive for the deposit and dissemination of scientific research documents, whether they are published or not. The documents may come from teaching and research institutions in France or abroad, or from public or private research centers.
L'archive ouverte pluridisciplinaire HAL, est destinée au dépôt et à la diffusion de documents scientifiques de niveau recherche, publiés ou non, émanant des établissements d'enseignement et de recherche français ou étrangers, des laboratoires publics ou privés. 


\title{
Mixed Alkali Effect in $\mathrm{Na}_{2} \mathrm{O}-\mathrm{Li}_{2} \mathrm{O}-\mathrm{SiO}_{2}$ Glasses Studied by Isothermal Mechanical Spectroscopy
}

\author{
C. Tardif, L. Arnault and A. Rivière \\ Laboratoire de Mécanique et de Physique des Matériaux, URA 863 du CNRS, ENSMA, BP. 109, \\ 89960 Futuroscope cedex, France
}

\begin{abstract}
Several studies of internal friction have been performed on silicate glasses. This work has the specificity to refer to isothermal mechanical spectroscopy over a large frequency range and for temperatures between $290 \mathrm{~K}$ and $520 \mathrm{~K}$. Experiments were carried out with a single alkali silicate glass and two mixed alkali silicate glasses in order to observe the mixed alkali effect, to follow its evolution versus alkali ratio and to deepen the knowledge of the mechanisms involved. According to this, internal friction spectra were shown to be dependent on the measurement temperature and the relaxation parameters were determined with greater accuracy. We also proved that non bridging oxygens peak is still present in mixed alkali glasses and that the relaxation mechanism for mixed alkali effect is related to couples made by the two alkali oxides.
\end{abstract}

\section{INTRODUCTION}

Many experiments on internal friction in glasses exhibited two relaxation peaks in single alkali silicate glasses [1]. The first one, $P_{1}$, at low temperature $(233 \mathrm{~K}$ to $248 \mathrm{~K})$ is assigned to the stress induced diffusion of alkali ions and called "low temperature peak". The second one, $\mathrm{P}_{2}$, appears at higher temperatures and is often called "non bridging oxygens peak" but its origin is still debated. The addition of a second alkali ion alters spectrum and leads to a new relaxation phenomenon representative of the mixed alkali effect and characterized by a third relaxation peak $[2,3,4]$. The magnitude of this effect varies directly with the alkali ions ratio and is generally explained with cooperatives movements of complexes formed by the two dissimilar alkali ions [5]. However, mechanisms responsible for this effect are not clearly established. Therefore the purpose of our work is to observe the mixed alkali peak in $\mathrm{Na}_{2} \mathrm{O}-\mathrm{Li}_{2} \mathrm{O}-\mathrm{SiO}_{2}$ glasses, to follow its evolution and modifications in accordance with the alkali concentrations ratio.

\section{EXPERIMENTAL PROCEDURE}

The studied glasses are of $(1-\mathrm{x}) \mathrm{Na}_{2} \mathrm{O}-\mathrm{xLi} \mathrm{i}_{2} \mathrm{O}-3 \mathrm{SiO}_{2}$ type. Experiments were carried out on glasses for three different values of $\mathrm{x}(0 ; 0.25 ; 0.5)$. We used an inverted torsion pendulum and performed internal friction measurements as a function of the vibration frequency at fixed temperature. The frequency range with this subresonant method extends from $10^{-4} \mathrm{~Hz}$ to $31.6 \mathrm{~Hz}$ and the temperature range from $293 \mathrm{~K}$ to $547 \mathrm{~K}$. With the subresonant method, internal friction, $\mathrm{Q}^{-1}$, is equal to $\tan \varphi$ where $\varphi$ is the phase lag between applied stress and resulting strain. The pendulum has yet been described in details by Woirgard and al. [6]. Torsion vibrations are driven by a mechanical part and an electronical part manages the signal and realises data acquisition. The accuracy of $\mathrm{Q}^{-1}$ is about $2 \times 10^{-4}$. The strain is $5 \times 10^{-6}$. The samples are flat bars whose dimensions are $1.5 \times 5 \times 50 \mathrm{~mm}^{3}$. 


\section{RESULTS}

Experiments on single alkali silicate glass $\mathrm{Na}_{2} \mathrm{O}-3 \mathrm{SiO}_{2}$ were carried out between $290 \mathrm{~K}$ and $514 \mathrm{~K}$. Figure 1 presents the relaxation peak, which shifts to high frequencies when the temperature of measurements increases. From the isothermal data we represent the curve internal friction versus temperature. Figure 2 shows the peak obtained for $\mathrm{f}=0.1 \mathrm{~Hz}$. After background substraction the magnitude of the peak is about $50 \times 10^{-4}$. Its half height width covers two decades.

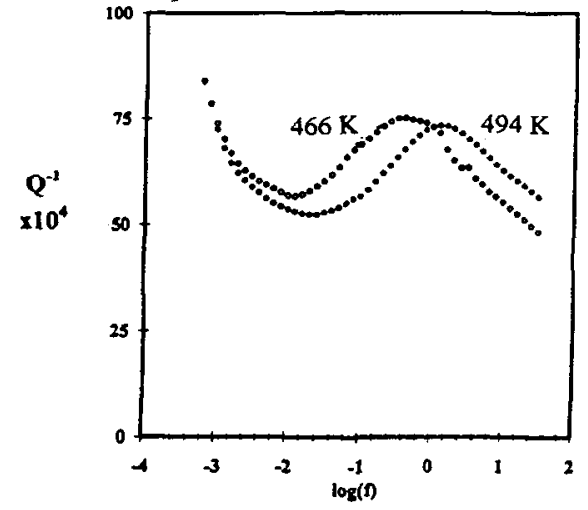

fig 1 .

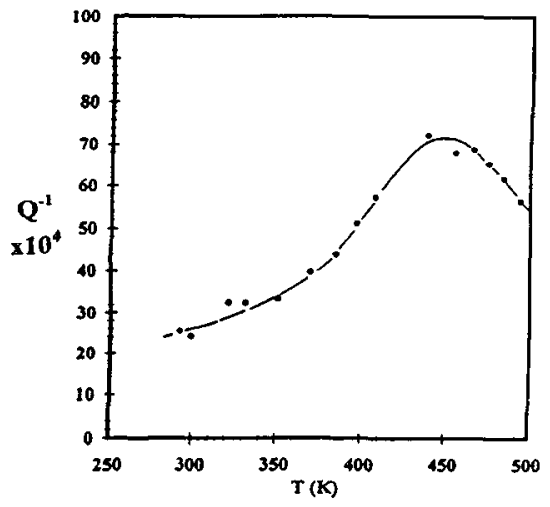

fig 2.

Figure 1 : Internal friction versus $\log (f)$ in single alkali silicate glass for two temperatures.

Figure 2 : Internal friction versus temperature for $\mathrm{f}=0.1 \mathrm{~Hz}$ in single alkali silicate glass.

Concerning $0.75 \mathrm{Na}_{2} \mathrm{O}-0.25 \mathrm{Li}_{2} \mathrm{O}-3 \mathrm{SiO}_{2}$ glass, isothermal experiments were carried out between $295 \mathrm{~K}$ and $438 \mathrm{~K}$. A wide and asymmetric peak, whose height is $120 \times 10^{-4}$ (after background substraction), is observed (fig.3). The half height width covers 3.5 decades. Figure 4 represents internal friction ${ }^{\prime} \mathrm{Q}^{-1}$ versus temperature for $\mathrm{f}=0.1 \mathrm{~Hz}$.

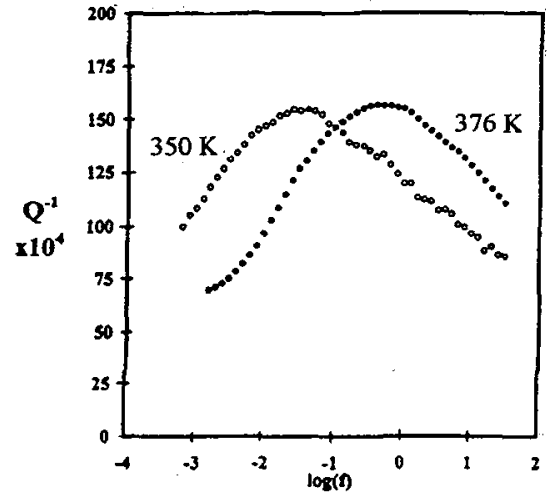

fig 3 .

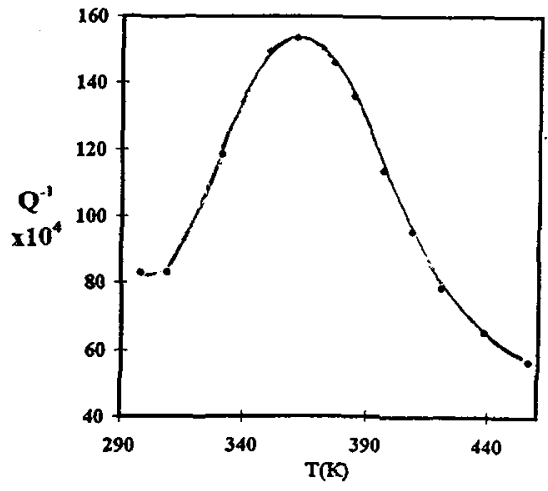

fig 4 .

Figure 3 : Internal friction in $0.75 \mathrm{Na}_{2} \mathrm{O}-0.25 \mathrm{Li}_{2} \mathrm{O}-3 \mathrm{SiO}_{2}$ glass. versus $\log (\mathrm{f})$ for different temperatures Figure 4 : Internal friction in $0.75 \mathrm{Na}_{2} \mathrm{O}-0.25 \mathrm{Li}_{2} \mathrm{O}-3 \mathrm{SiO}_{2}$ glass. versus temperature for $f=0.1 \mathrm{~Hz}$. 
Experiments on $0.5 \mathrm{Na}_{2} \mathrm{O}-0.5 \mathrm{Li}_{2} \mathrm{O}-3 \mathrm{SiO}_{2}$ glass were performed from $290 \mathrm{~K}$ to $547 \mathrm{~K}$. As shown in figure 5 , we observe again a wide asymmetric peak. The height of the peak is about $140 \times 10^{-4}$ and half height width covers four decades.

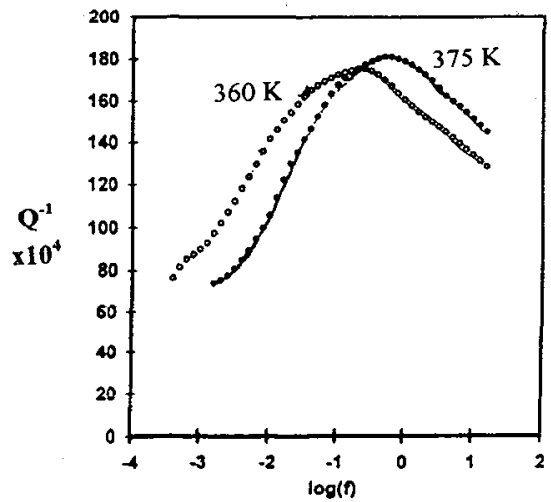

Figure 5 : Internal friction spectra versus $\log (f)$ in $0.5 \mathrm{Na}_{2} \mathrm{O}-0.5 \mathrm{Li}_{2} \mathrm{O}-3 \mathrm{SiO}_{2}$ glass.

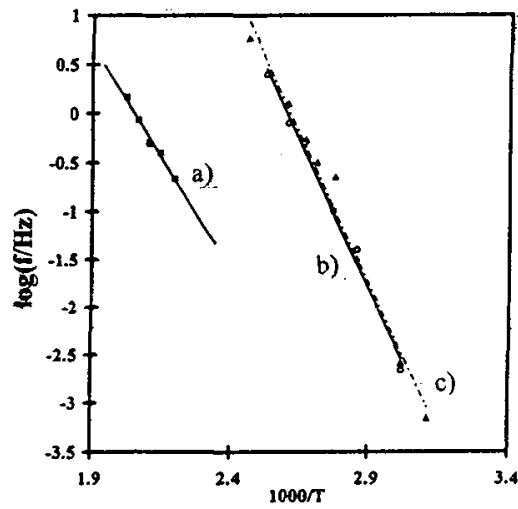

Figure 6 : Arrhenius plots for a) $\mathrm{Na}_{2} \mathrm{O}-3 \mathrm{SiO}_{2}$ b) $0.75 \mathrm{Na}_{2} \mathrm{O}-0.25 \mathrm{Li}_{2} \mathrm{O}-3 \mathrm{SiO}_{2}$ c) $0.5 \mathrm{Na}_{2} \mathrm{O}-0.5 \mathrm{Li}_{2} \mathrm{O}-3 \mathrm{SiO}_{2}$.

Figure 6 shows the three Arrhenius plots relative to the three observed peaks. The activation energies and the limit relaxation times $\tau_{0}$ (table $\mathrm{A}$ ) are deduced from these plots.

Table A : Relaxation parameters of the three alkali samples.

\begin{tabular}{|c|c|c|c|}
\hline & $\mathrm{Na}_{2} \mathrm{O}-3 \mathrm{SiO}_{2}$ & $0.75 \mathrm{Na}_{2} \mathrm{O}-0.25 \mathrm{Li}_{2} \mathrm{O}-3 \mathrm{SiO}_{2}$ & $0.5 \mathrm{Na}_{2} \mathrm{O}-0.5 \mathrm{Li}_{2} \mathrm{O}-3 \mathrm{SiO}_{2}$ \\
\hline activation energy $(\mathrm{eV})$ & 0.93 & 1.20 & 1.20 \\
\hline limit relaxation time (s) & $3.96 \times 10^{-11}$ & $3.121 \times 10^{-17}$ & $2.19 \times 10^{-17}$ \\
\hline
\end{tabular}

\section{DISCUSSION}

According to our opinion the $\mathrm{Q}^{-1}$ peak observed in single alkali glass is the peak called "non bridging oxygens peak" which is generally observed in this type of glass. Some earlier studies [7] gave the activation energy values 1.2 or $1.3 \mathrm{eV}$ for $P_{2}$ which is higher than the values obtained from fig.6. 
This difference may be explained by the fact that, contrary to our experiments, these earlier works have been carried out at fixed frequency in temperature sweep. The low value of $\tau_{0}$ may be the consequence of a large defect.

The figure 7 represents the internal friction spectrum for $0.5 \mathrm{Na}_{2} \mathrm{O}-0.5 \mathrm{Li}_{2} \mathrm{O}-3 \mathrm{SiO}_{2}$ glass with $\mathrm{f}=0.032 \mathrm{~Hz}$ We can see that the bottom of the peak has a slight shoulder peak at high temperatures. According to figure 8 , we note that this is connected to the "non bridging oxygens" peak. This tends to prove that the "non bridging oxygens peak" is still present in mixed alkali glasses.

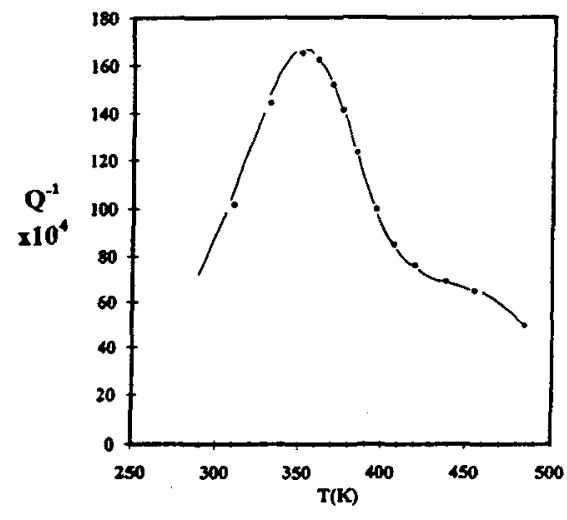

fig 7

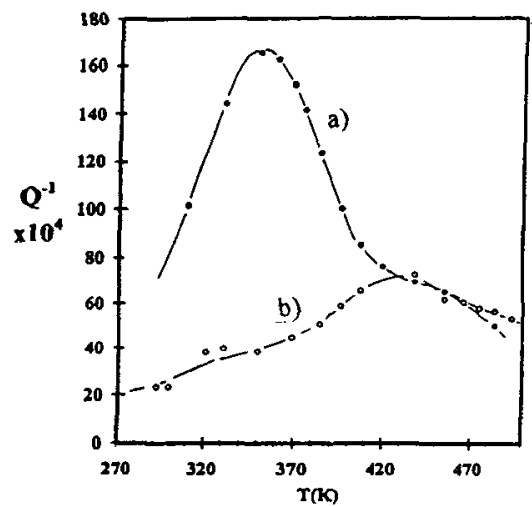

fig 8 .

Figure 7 : Internal friction versus temperature for $f=0.032 \mathrm{~Hz}$ in $0.5 \mathrm{Na}_{2} \mathrm{O}-0.5 \mathrm{Li}_{2} \mathrm{O}-3 \mathrm{SiO}_{2}$ glass.

Figure 8 : Internal friction spectra for $\log (f)=-1.5$ in a) mixed alkali silicate glass b) single alkali silicate glass.

As shown in table $A$ the two peaks obtained for mixed alkali glasses have the same activation energy, and $\tau_{0}$ limit relaxation time. Therefore, we conclude that it is the same relaxation phenomenon observed in the two studied mixed alkali glasses. The value of $\tau_{0}$ and the asymmetry of the peak tend to enhance theory based upon correlated mechanisms. Especially, the activation energy is twice what it is expected for the self-diffusion of one alkali ion.

Next, we note that the mixed alkali effect is more intense for $x=0.5$ than for $x=0.25$. This could prove the dependence upon alkali ratio and give a start to better know the effect mechanism : as the effect is more important when alkali oxides are on equal proportions, we may suppose that the relaxation mechanism requires couples made by the two ions.

\section{References}

[1] Day D.E., Zdaniewski W.A. and Rindone G.E., The Internal Friction of Glasses, J. Mat. Sci.. 14 (1979) 763-775.

[2] Steinkamp W.E., Shelby J.E. and Day D.E., Internal Friction of Mixed Alkali Silicate Glasses, J. Am. Cer. Soc., (1967) disc. and notes.

[3] Stevels J.M., Non Crystalline Solids, (1977) pp. 18-31.

[4] Day D.E., Mixed Alkali Glasses - Their Properties and Uses, J. Non-Cryst. Sol., 21 (1976) 343-372.

[5] Perez J, Gobin P.F., Phénomènes de Relaxation et Frottement Intérieur dans les Solides Vitreux, Rev. Phys. App., 12 (1977)

[6] Woirgard J., Sarrazin Y., Chauvet H., Rev. Sci. Instrum., 48 (1977) 1322.

[7] Day D.E., "Amorphous Materials", Wiley (N.Y.) 1972, Douglas R.W. and Ellis B. editors. 